\title{
Why Economics Is a Science: Information, the Grand Unifier
}

\author{
Bhekuzulu Khumalo \\ Private Researcher, Toronto, Canada \\ Email: bhekuzulu.khumalo@gmail.com
}

Received 24 December 2015; accepted 21 February 2016; published 24 February 2016

Copyright (C) 2016 by author and Scientific Research Publishing Inc.

This work is licensed under the Creative Commons Attribution International License (CC BY). http://creativecommons.org/licenses/by/4.0/

c) (†) Open Access

\begin{abstract}
Knowledge has always been the primary resource of human beings. The economy has always been a knowledge economy. For those having a firm grasp of knowledge know that using a stick to fend off a wild beast takes knowledge, just as landing a robot on mars takes knowledge. Knowledge is nothing more than information that we know. There is therefore a difference between information and knowledge. It is the concept of information that unites economics with all other sciences, this is only because everything is information, and information is the core of any science.
\end{abstract}

\section{Keywords}

Commodified Information, Consistency, Discreteness of Information, Independence of Information, Information, Information Package, Knowledge, Science

\section{Introduction}

There has always been a deep debate concerning the scientific credentials of economics. Often economics is degenerated by other social scientists and natural sciences for pretending to be a science and desiring to be taken seriously as a science. Economics of course has its own defenders usually economists themselves. This debate has been going on for some time and has never really dissipated since the founding of modern economic theory. The literature is abundant and more so today than ever before thanks to personal blogs that can be written and viewed over the internet and the world wide web.

Take an article written by Liam Halligan entitled “Time to stop this pretence-economics is not a science", for the newspaper The Telegraph in October 2013 [1]. Halligan commented that "Yes, it obviously makes sense that share prices reflect all available information-which Fama stressed. But they also clearly reflect rumours, supposition, herd-instinct, prejudice, hubris, pessimism and a myriad of other immeasurable qualitative factors, including occasional madness, which Fama largely ignores”. This argument is basically the core of argument of 
those saying that economics can never be a science. But when we take into consideration information this argument will largely fall apart as one will realize by the end of this paper, when the relationship between knowledge and information is more fully comprehended.

Take the comment made by Atul Singh writing in his own blog in an article entitled "Economics is an Art, Not a Science" [2], Singh argues "what explains the two World Wars, the Holocaust or Pol Pot? Why do we eat the extra ice cream instead of going for a run? The belief among economists that human beings are terribly rational is highly irrational”. This argument will also be debated by the end of this paper as we will attempt to look at what is information.

Quora is an Internet based software that allows people to ask questions and experts to answer those questions. On this website the questions is economics a science? If not, what is it? is asked. Luis Figueroa [3] answers the question and makes an important comment, the great Economist, John Maynard Keynes, believed human economic behavior was driven by "animal spirits". How do you model animal spirits? The great Yale Economist, Irving Fisher, and the manager of its investment fund said just before the stock market crash and subsequent Great Depression, "Stock prices have reached what looks like a permanently high plateau. I do not feel there will be soon if ever a 50 or 60 point break from present levels, such as (bears) have predicted. I expect to see the stock market a good deal higher within a few months.” It is a fair question, how come mainstream economists nearly never truly predict the bank events.

However, Figueroa himself answers his own question from the quote of he made of Fisher. Fisher says "I do not feel there will be soon if ever a 50 or 60 point break from present levels, such as bears have predicted." Clearly there where economists with the opposing view and Fisher was brushing them aside.

The same question on Quora is answered by Sylvia Nasar [4]. Her answer is in favor of economics being considered a science. An important quote from her answer says "Sure it is-if a science is a method for breaking down big complicated problems into smaller, more tractable ones and for dealing with them, one at a time, systematically, that is, an engine of analysis, a tool for discovering truths rather than a body of dogma." From her answer clearly there are different opinions when it comes to answering the question is economics a science?

Amidst all this debate other actors are entering the argument, trying to answer the question is economics a science by uniting the two subjects into what is known as econophysics. The aim of econophysics is to take out the doubt of economics as a science from the mind of doubters, the argument being the discipline is serious enough to be taken seriously by physicists, what more is needed to convince the world. An idea that is scoffed at by the likes of Atul Singh [2] who further writes in his article "Economics makes a false claim to be a science just like Political Science. The truth is economics suffers from physics envy. In physics, hypotheses can be tested, but there is no way to measure the veracity of economic formulas. Human actions are not easily measurable, the variables that determine economic activity are not easily determinable, correlation is often confused to be causality and experiments are not exactly possible, unlike physics. Truth be told, mainstream economics is yet another religion. Just like Marxism, it is a religion without a god. It rests on assumptions that are not supported by evidence."

Econophysics is a reality despite the protests of the likes of Singh. In a paper written by Farmer and others entitled "is economics the next physical science" [5], they have this to say about the two disciplines economics and physics, "despite the fields' long history of association, the substantial contribution of physics to economics is still in an early stage, and we think it fanciful to predict what will ultimately be accomplished.” This is an unfortunate view because it clearly implies the relationship is one way, economics alone is benefitting from the association of the two disciplines but when we understand knowledge we find that the relationship is two ways. However, one must recognize econophysics for what it really is, it is a branch of econometrics.

Focardi has a lot of faith in econophysics contributing to put economics on a more scientific footing. In his paper "Is economics an empirical science? If not, can it become one?" [6] Focardi had this to say in his conclusion, "We successively explored new ideas that hold the promise of developing economics more along the lines of an empirical science. Econophysics, an interdisciplinary effort to place economics on a sure scientific grounding, has produced a number of results related to the analysis of financial time series, in particular the study of inverse power laws. But while econophysics has produced a number of models, it has yet to propose a new global economic theory." What many fail to miss when dealing with the relationship between economics and science, be that science, physics, chemistry or biology the relationship need not be mathematical.

When we look at knowledge we should realize that the relationship is a pure scientific relationship not always mathematical but mathematics has a lot to do with it. Every discipline must be unique, you cannot turn econom- 
ics into physics, or chemistry, or biology, we are after all dealing with human settlements and relationships not ant colonies and ant relationships. We know from physics, particularly from those who deal with quantum physics, information is everything. To have a firm grip on the concept of information it would be wise to pay attention to the video by Ray Muon posted on youtube entitled "Physics of Information - Quantum Entanglement, Black Holes and Holographic Universe" [7]. Information is just information and will always behave the same no matter in what discipline one understands it in. Knowledge after all is just information that is known to us.

\section{The Definition of Economics and the Importance of Knowledge}

What is economics? The current accepted definitions of economics can all trace the definitions they give from a paper written by Lionel Robbins back in 1932 entitled "An Essay on the Nature and significance of Economic Science" [8]. The definition given in this paper is "economics is the science which studies human behavior as a relationship between ends and scarce means which have alternative uses."

Until we fully comprehended the importance of knowledge the definition given by Robbins will always hold. Accepting the crucial role that knowledge plays in economics, to make clear from the beginning how important knowledge is Bhekuzulu Khumalo wrote a paper "Defining Economics in the Twenty First Century" [9] he defined economics following the accepted logic of Lionel Robbins as "economics is the study of how humans use knowledge to identify resources and use these scarce resources to create, using knowledge, commodities and distribute them among people.” In reality even this definition might be too long, it might be easier just to say economics is the study of the flow of commodified knowledge in society.

When one says economics is merely the study of commodified knowledge it should not sound high brow language. When one purchases any good, that good is a good because of knowledge. A watch is the result of knowledge; a watch can be considered a packet or package of knowledge. This package includes material properties and physics property concerning springs, and aesthetics, that appealing to human vanity, all this knowledge is commodified to give us a watch and we can tell the time. Everything begins with commodified knowledge, flour is commodified knowledge, just as that stick the cavemen used to fend of wild animals is merely commodified knowledge.

\section{A Perspective of Knowledge}

Economics is the study of the flow of commodified knowledge in society. Knowledge is what we know. When one is thinking as an economist, knowledge is what creates goods and services, the cavemen chose a particular type of stick to be a commodity, not all sticks, others where not even good enough for firewood. Economists are interested in that part of knowledge that becomes a commodity, the commodifying process as well. Knowledge for an economist is information that is known and commodified. Now what is a good? if one asks for directions and they offer $\$ 10$ for directions, those directions have been commodified, just as the information that resulted in creating the space station has been commodified knowledge. It is all just information and manipulation of information.

Speaking in the language of science information is everything. Science would not be possible if everything was not information. We extract information about a thing for it to become knowledge, we extract information from information for us to understand something. With basic information a stick is a great weapon. With greater information extracted we realize we can make charcoal from that stick, and with further information extracted we realize we can make a type of paper from that stick, it is all about how much information is extracted that creates the knowledge base of a society or individual.

Information is commodified when it becomes of use to the human being. At the beginnings of humanity, a strong stick was a particularly valuable commodity for walking and keeping wild animals away, it was no garden of Eden. That same process of commodifying information has led us to genetic manipulation, soon of sperm and egg to create "better" human beings. Knowledge economics deals with the understanding of this process of commodifying information.

As human beings we need to be able to differentiate between the different types of information that we encounter. We need to know the properties of the information for it to be useful to us, in other language we can say we need to know the different properties of the material, this of course is the language of epistemology. In the language of science, the word material is replaced with the word information, a much broader and more thorough concept. 
Material is a philosophical term, originating with the first philosophers who also where surrounded by highly religious societies. They attempted to combine science, philosophy and religion. According to original philosophy the word material was considered but of many realms, the material realm, the spiritual realm, and the realm of the gods. Science does not yet recognize these different realms, anything that can be known is just information, there is no doubt what is being discussed. The thing being discussed when talking about information is something that we can extract information from.

Take a stick, the practical information for the most ancient of humans was the information they readily extracted, was the stick, strong, sturdy enough not to break on impact, it had to be able to deliver a tremendous blow on a wild animal and not break in case there was a pack of wild animals. This was the ideal stick and one needed to be able to judge that. Modern man has designed tools, thanks to information that has been extracted over countless centuries, these tools can go further and let us know the very basic information that makes that stick. These tools built by man's knowledge have allowed human beings to successfully extract information about sub atomic particles, allowing human beings to be on the verge of a world where quantum and nano technology will play a significant part in the goods that will be available in the market. These sub atomic particles of course are what go into creating the stick. Goods are just useful knowledge for lack of a better term. This was explained in the paper "Point X and the Economics of Knowledge", written by Bhekuzulu Khumalo [10].

The language of science allows us to appreciate the true significance of information over and above the word material. Our very survival has always been about extracting information from our surroundings and commodifying that information that we could. Extracted information becomes knowledge.

This ability and process of differentiating the material, differentiating information allowed the most ancient of humanity to pick up a stick against a lion or a wolf rather than throwing water at the ferocious beasts, probably enrage them more for poor judgement. It is this same process of differentiating different packages of information that we have the ability, the knowledge to send a probe to mars and beyond the solar system. It is deeply flawed and a lack of understanding of knowledge to believe human beings have recently entered a knowledge economy. This flaw off believing knowledge only now became central to human survival and economics it does not allow one to fully appreciate the concept of information, that information is everything. This hinders the economist thought pattern and does not allow economics to be fully a science. Information is central to science.

It is when we realize and accept the obvious that knowledge is that part of information that we know, or that mankind knows. However, if one only begins to believe that we are only now entering the knowledge economy one cannot appreciate the fact that it took knowledge for a cave man to understand that a stick can ward off wild animals, one cannot appreciate the relationship between information and knowledge, and that information is everything. Knowledge economics explains the relationship between information and knowledge in one aspect.

\section{Point X; Information and Knowledge [10]}

Point $X$ is an information package that is known to man. It is mankind's knowledge or an individual's knowledge. It does not matter the size of this information package. The knowledge package could be everything that an individual or a society knows, or simply the fact that $3+2=5$, or that water is made up of two particles of hydrogen and one particle of oxygen. No matter the size, the knowledge package behaves the same way.

A package of knowledge is whole, it is discrete. There is no such thing as half knowledge, what you know is your information package, what is half of knowledge, half of a fact. Those are just conveniences for lay man's language, but in reality knowledge is discrete. That a certain human only knows that $1+1=2$, that is all the information that they know, that is their knowledge package. What is half of knowing $1+1=2$ ? there is no such thing, if one answers one, then they have misunderstood the question and the information that led to the question. What is half an egg, or sperm, or electron, there is no such thing, information is discrete, knowledge, information that we have extracted cannot disobey this law, it is either one knows something or does not. Something is something or it is not. False information can never be extracted because it does not exist, but false knowledge can exist because knowledge is a construct of the human mind, false knowledge is made up information, it does not exist in reality. Half of information does not exist, it can only be made up by the human mind.

By observing and understanding what we are observing, the total extracted information grows, be it of the individual or society. We know this because we have advanced far from cavemen as humanity, the amount of knowledge, extracted information is enormous compared to the amount of extracted information cavemen had. As individuals we know we know more as adults than we did as toddlers. 
One might be tempted to play the devil's advocate and ask why a knowledge economist would be interested in the fact that knowledge is discrete. The reason is that such an economist needs to know the properties of what it is that creates commodities, it is knowledge that creates commodities, goods and services. Therefore, in one aspect it is important to know the properties of what is being commodified. It is information that is being commodified, to be complete in any scientific discipline, it would not be wrong to say one should at the least understand what information is, science deals solely with understanding and extracting information. To be one who seeks to understand how information becomes a commodity one needs to know the properties of information, the properties of what they are dealing with so to speak.

Knowledge is discrete because knowledge is information and information is discrete. As knowledge is extracted information, you cannot know half of something, because that information can never be extracted.

Let some human only understand that $1+1=2$. If somebody teaches that certain individual that $2+1=3$ clearly this information package is different from $1+1=2$. The human being who has been taught that $2+1=3$ has gained knowledge package, they now know that not only $1+1=2$, but also that $2+1=3$. There is a discrete gain in knowledge. The increased gain in knowledge can be represented as two information packages $1+1$ $=2$ and $2+1=3$, or as one knowledge package represented by $1+1=2,2+1=3$ as illustrated in Figure 1 .

That information is discrete allows us to be able to learn. Knowledge being discrete follows that information is discrete and vice versa, almost dealing with the same thing when talking of information and knowledge. One can see from Figure 1 that information can be isolated, $(1+1=2) \neq(2+1=3)$. The bigger set that contains both $(1+1=2),(2+1=3)$ can be broken down to $(1+1=2)$ and $(2+1=3)$, this is the isolation of information and it allows us to extract information otherwise it would be impossible to learn. If we could not isolate information, given Figure 1, it would mean that to know $1+1=2$, one would also have to know $2+1=3$ at the same time, exactly the same time, an impossibility, but luckily information is discrete we can first learn $1+1=$ 2 and then $2+1=3$ because it is easier for us to learn in that manner but theoretically one could learn $2+1=3$ before learning $1+1=2$.

The example above about isolation of information given Figure 1 is simply to simplify the scenario. As humans we build upon simplicity. The real scenario of course is that to learn what is considered a simple fact like 1 $+1=2$, if information could not be isolated one would have to know everything instantaneously just to also know that $1+1=2$.

Information can be isolated and this allows us to learn, this allows us to extract information suitable to our minds, our minds are not capable of knowing everything instantaneously. However, the process of learning is that we learn what we consider the most basic steps, but in reality all information is worth the same amount. There is no information more important than any other piece when it comes to value to creation. Though we value commodities at different prices, the importance of each piece of information is equally important to existence. That is because if a single piece of information was changed, all existence changes. Therefore, the fact that $1+1=2$ is equally as important as say $\mathrm{E}=\mathrm{MC} 2$. This is indeed a very serious matter, imagine if $1+1 \neq 2$, it would be a whole different kind of existence.

One could argue above that we have only talked about knowledge, $1+1=2$ is an abstract conceptualization, a tool for us to understand information, mathematics. If information is everything the same principles of isolation must also apply with what we consider the material, not abstractions like mathematics. If information could not be isolated, it would be impossible to learn things. But because information can be isolated we can tell the difference between a stick and water, we can tell the difference between and electron and a photon, between a photon and a stick. All this would be impossible if information could not be isolated. We can isolate knowledge because we can isolate information.

That information can be isolated is the basis of science. If information could not be isolated what would be

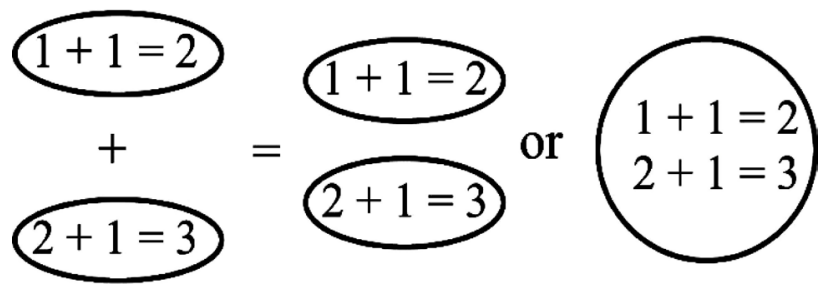

Figure 1. Discreteness of information. 
there to investigate? Science is the isolation of information so that we can understand our existence better and finally commodify that information to create a commodity. The same principle applies to knowledge that it can be really broken down to understand what 1 is, one is just a candy.

It is a given that science would not exist without the isolation of information. All information can be isolated such that it stands alone, the atom has been isolated and humans have gone even further isolating protons, photons and other subatomic particles, extrapolation and logic says everything can be isolated. That means the process of commodifying knowledge will continue until everything, until all information is isolated, including all what we consider forces, everything is information and everything can be isolated until it is just that phenomenon and nothing else. After isolation it is then that a phenomenon can be commodified. It is because we understand how knowledge behaves we understand how information behaves, the packages of information, they must behave like knowledge because knowledge can only be isolated because information can be isolated.

\section{Independence of Information}

Having understood that information can be isolated or it would be impossible to learn anything, we would need Eureka moments from knowing nothing to know everything instantaneously. It is also important to mention the independence of a package of information. Information can only be isolated because each package of information is independent from another package of information. By independent it means it exists outside the determinants of anything else, of other packets of information.

Take Figure 2. Figure 2 is just the answer to Figure 1. We have an information package comprising of $(1+1$ $=2),(2+1=3)$ that can be isolated into discrete independent packages comprising $1+1=2$ and $2+1=3$. We understand the principle of why information packages can be isolated. But the reason why they can be isolated is because information packages are independent of each other. In Figure 2 all three sets are independent of each other. If one feels more comfortable calling information packages sets, it would not harm the understanding of the principles being discussed.

It is readily understood that $1+1=2$ is independent from $2+1=3$, but how can they both be independent of the big package that contains them both. Take $1+1=2$, in the larger information package you can do 2 things, one knows two things, they are completely different from each other. Though stainless steel contains iron, it exists independent of iron, its existence is based on the laws of information. Iron exists because the laws of information say that if you order information in such a way you will get iron. Pure iron like stainless steel both do not exist in "nature". If you order information in another fashion you will get stainless steel. This law exists and has to be independent of the law that governs iron. If a law of existence depends on another it would mean one law is more important than another which simply would not be true. If $1+1 \neq 2$ it would be a completely different existence, in exactly the same degree of importance as $\mathrm{E} \neq \mathrm{mc} 2$. If information could only be isolated but not independent there would be only one way to extract information. If for example there is no independence of information, if Figure 2 exists and there is no independence just isolation, we could never have Figure 3.

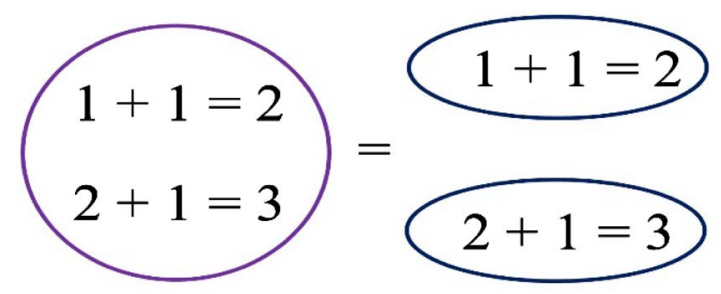

Figure 2. Independence of Information 1.

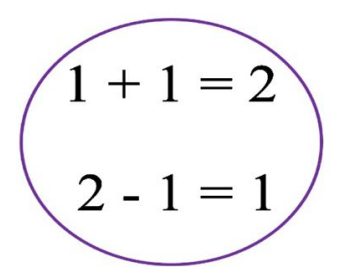

Figure 3. Independence of Information 2. 
Figure 3 of course represents a knowledge package containing information $1+1=2$, and $2-1=3$. With no independence of a package of information if Figure 2 is true then we could never have Figure 3 because if information is not independent to have Figure 3 we would also need $2+1=3$ because there is no independence. But in reality one could first learn $1+1=2$ and instead of next learning that $2+1=3$, one could just as easily first learn that $2-1=1$.

Don't confuse the art of learning and behavior of knowledge. True one learns addition first because it is easier to comprehend than say multiplication, but one could easily first be taught multiplication instead of addition, but it would be difficult because of the way our minds are structured. This should not sound odd. We first learnt the complex properties of a stick, that it is solid, and can be rigid before we learnt the very basic information of the stick, the basic information of a stick is that it is made up of particles that are identical to particles that make up all other more complex information. It is just the manner of the arrangement of the information that separates a human being and a stick, that separates water and a rock.

Therefore, when it comes to a stick, it is easier for us to grasp the more complex information that the stick is solid and different from water than to grasp the basic, the particles that make a stick are identical to the particles that make up water. When we say particles, we can say and be even more correct, we can say the basic information that makes a stick is the same as the basic information that makes water, the arrangement of the information is different. A particle is just information and each particle is known because we have isolated information, what did a Roman understand about photons? We could only isolate photons because each package of information is independent.

This independence of a knowledge package allows us to isolate information, this allows us to learn and be able to investigate information, but importantly for economic development it means that we can only extract information that is useful and do not have to go through the entire process. A human can manufacture a phone without going through the process that Meucci the inventor of the phone had to go through. An industrializing country does not need to start with a steam locomotive, there is better technology around. This is all possible because a package of information is independent from other packages of information.

A package of knowledge is independent because a package of information is independent, it is important to stress that knowledge is just information that we have extracted from existence. This independence of a package of information is what allows variety in the universe. If information packages where not independent it would mean that information can only be arranged in a certain manner, and because there is no independence all information packages would be the same everywhere.

As information is independent it means at the most basic levels, particles do not have a pre-arranged manner in combining, hence we have variety at the sub atomic level. There is also variety at the atomic level, we have hydrogen atoms, nitrogen, uranium, gold, magnesium, we have all the elements at the atomic level. At the molecular level there is still variety. Information is so varied that even at the species level we have variety. All humans are not the same, there are no identical humans, in some manner there is always differentiation, we are each independent information packages. Information is independent from the smallest information package the basic particles, to largest densest information packages like a galaxy. All can be isolated and information extracted from them. Not even 100 years ago did anybody in such large numbers believe there was possibility of life on different planets. We are detecting planets light years away orbiting different stars further and further away. We are extracting more and more information from the galaxy.

Given the circumstances though information is independent, it must be consistent in its behavior. Each differentiation of information shows a consistent behavior given circumstances and can thus be recreated if similar conditions can be recreated. Thus oxygen is created given a particular set of circumstances, recreating these exact circumstances will create an atom of oxygen. Given certain circumstance zinc atoms will be created. Because of consistency every time those circumstances occur, zinc atoms will be created. Consistency means a thing is that thing and will not randomly change from being that thing.

A zinc atom is a zinc atom, it will not under normal conditions be an oxygen atom the next time period, it will always be zinc because of the circumstances that occurred that say given certain conditions information will be arranged in such a manner that it behaves in a manner consistent to what human beings have named zinc. The caveman can be pretty sure that in the morning the stick will still be a stick and not be water or a snake, that is the law of consistency. As knowledge is information that we have extracted, it follows too that a knowledge package must be consistent, otherwise again it would be impossible to learn. Consistency is the pattern.

Without consistency it would be impossible to learn because if something can be anything in the next time 
period then we can only know something for that time period, we would always be relearning. But, because of consistency we can be sure that in the next time period an airplane will still be an airplane. The relationship that is expressed as $1+1=2$ will be just that in the next time period. All information packages are consistent be it an electron, a type of engine, a lion, and understanding that $1+1=2$, as information packages they all have the same properties.

Knowledge economics allows us to understand that when it comes to discreteness of a package of information, isolation of a package of information, independence of a package of information, and consistency of a package of information, knowledge and information behave the same and have to behave the same because knowledge is information that we have extracted.

The Infinite and knowledge: Figure 1 above illustrates what happens when somebody who only knows $1+1$ $=2$ is told/ taught that $2+1=3$. What happens when somebody who already knows that $1+1=2$ is told that 1 $+1=2$. This is illustrated in Figure 4.

Figure 4 is an illustration of what happens when somebody is told what they already know. When somebody is given knowledge that they already know. The middle part is just an illustration it does not exist. The answer then to a knowledge package that is given and is already known is that there is no gain. This is only peculiar to knowledge, that adding the same thing is the same thing. This does not happen with information in general, adding the same information leads to an increase.

Take an information package such as say an atom, say one nitrogen atom. There can be three nitrogen atoms, even trillions one can count them. This is pure information. Those who study nitrogen know physical attributes concerning nitrogen, that is why they can count them, as they are differentiated from other elements. However, the knowledge about the properties of nitrogen is known, it does not need to be identified with each new nitrogen atom because one already knows what it is, the knowledge has become timeless to that individual. To tell them how a nitrogen atom behaves and its physical properties adds nothing new to somebody who studies nitrogen. That is what Figure 4 basically illustrates.

We know what an automobile is, we do not need it to be described each time we see a car on the road and have it pointed out constantly that this is a car. This means that when we add two atoms of nitrogen we get the answer $1+1=2$. However, when we add knowledge about nitrogen if somebody tells us what we already know we get $1+1=1$, and that is a real mathematical fact, you can prove it to yourself over and over again and again. The only logical answer for this is dimensions as was discussed in the paper "the concept of the mathematical Infinity and Economics" by Bhekuzulu Khumalo [11]. This has profound implications to know that the rate of change at infinite dimensions is zero, and that the actual rate of change, the mathematical derivative decreases with each increase in spatial dimensions, scientific dimensions. It has this implication because knowledge is information, it's laws, and principles are those of information. That is the gift of knowledge economics to the larger scientific community.

\section{Why Economics Is a Science}

Economics is a science because it studies the flow of information in a society. There is no larger a scientific concept than information. To study information is science, and there is no greater reason to claim to be a science than to study the flow of information in a society. Physics is basically about the understanding of the flow of information, how information is ordered and how it changes, and what causes that information to behave as it does. That is what economics does, understand how commodities, how goods and services are distributed. Goods are nothing but information packages, be they a car, or a flight on a plane, or a smart phone. All these things are just the arrangement of information packages, and a phone follows all the rules of information.

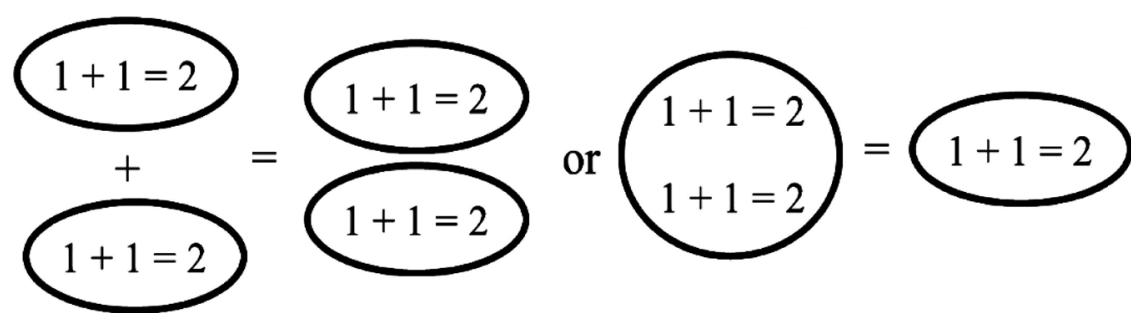

Figure 4. Adding the same knowledge. 
As everything is information "everything can be used to compute", Seth Lloyd [7]. We think today of computers as what is meant by computing, but an abacus was used for computing. A phone being just a package of information can also be used to compute. One can organize phones so that they can be used to show a measurement, a tally, a computation. A phone can easily be used as a weight on a scale to compute a balanced weight, a phone, any manufactured good is just information rearranged by human beings. True, modern computers use particles to compute and store information as it is far more convenient than using a phone or an abacus given the amount of knowledge we know. Now economics deals with how this commodified information, this commodified knowledge is distributed. This is the reason why economics is a science.

Being a science, economics must use the best tools of science available to it to understand this flow of information. It is not imitation; it is using the best tools available. Currently economists and physicists believe they can figure out better tools for economics that is a worthy cause. The more tools that become adapted to economics the better. It is not the use of so called scientific tools that makes economics a science, it is that economics studies the flow of information, that knowledge is information that is known should be clearly understood as has been laid out in this paper.

Just to make clear what knowledge is, and information, let us return to Liam Halligan's quote above he uses to denounce economics as not a science, "Yes, it obviously makes sense that share prices reflect all available information-which Fama stressed. But they also clearly reflect rumours, supposition, herd-instinct, prejudice, hubris, pessimism and a myriad of other immeasurable qualitative factors, including occasional madness, which Fama largely ignores.” Clearly Halligan does not understand information. Share prices reflect the aggregate information of what each shareholder values the company, it is a weighted aggregate. To argue that share prices also reflect rumor, herd instinct, prejudice, these are merely corrupters of information and therefore the market cannot calculate the correct prize, but the prize will always be set by the information available. If there is a rumor of a possible takeover, that information false or true will be reflected in the price of the shares. How many times do scientists get excited about an impeding break through when in reality break through is fifty years away? One must be as diligent as possible when dealing with information to extract the correct information. If one is going with the herd, that is the information that they have, that the herd knows best, there is no argument against economics being a science, there is no argument suggesting that economics does not deal with information, given that information is everything.

\section{Conclusions}

Economics is a science because it deals with understanding the flow of information. Economics deals with the flow of commodified information. Knowledge is information that humans have extracted and is known to them. Economics basically studies the flow of goods and services and a claim to those goods and services, goods and services are merely packages of information, what is termed as useful knowledge. That economics studies the flow of information is a sufficient condition for it to be considered a science.

The remainder of the conclusion shall be spent answering possible questions and doubts that are most likely to rise.

Information is what determines if something is a science. If the extraction and understanding of information is a main activity of that discipline it is a science. We can only understand information by extracting information from that information. Get used to the concept that everything is information. One could attempt to argue that methodology is more important for a discipline to be considered a science. The answer is no because it follows to extract information that the methodology has to be correct, you cannot extract information with a wrong methodology. It is the act of extracting information that makes a discipline a science. Extracting information in order to understand a phenomenon is science, it is not quantitative techniques that make something a science, quantitative techniques are a tool for extracting information.

"If methodology, experimentation was what makes a science a science, then one experimenting on methods to turn water into would be considered a scientist. One experimenting on how to break a loaf of bread such that it feeds 10,000 , why not $10,000,000$, is a scientist because they are carrying out experiments, then to qualify as a science the standards are low indeed. They will not find the spirits of the multitudes of past humanity with their electronic gadgets just because they are carrying out experiments. It is because economics extracts information about commodified information the reason, and sole reason why economics is considered a science, that information is being extracted is what makes a science a science.” (Bhekuzulu Khumalo) [12]. 
A science involves strictly the dealing with facts, with truth, with information, the discovery of these new truths, and the verification of these truths. Drawing an accurate map is just as much a science as entropy, genetic manipulation. The ancients who discovered separation of iron from its ore are as much scientists as understanding that $\mathrm{E}=\mathrm{MC2}$, those who first lit fire knew no mathematics as such, mathematics was not involved in the discovery, and repeating the action of starting a fire. This is in no way an attempt to underestimate the importance of mathematics and statistics to science.

"science is science because it's able to predict, you can't do that with economics, it's still left to probability" (Nkosana Mayisela) [12]. The question of predictability in science needs to come to its proper context regarding information. The issue of complexity of information must come to play. The sun is basically a burning ball of hydrogen, it is a simple package of information, and easily understood. The earth is far more complex information than the sun, it includes life, it's atmosphere being determined by life, the behavior of the earth's atmosphere is far more complex than that of the sun. Humans are far more complex information packages than a steel rod, the less complex the information package the more precise the science seems.

Humans being more complex require more complex techniques, more complex models, a more thorough understanding of the concept of the mathematical singularity. Take a boiler full of water. At certain temperatures we understand the behavior of the currents of water, currents caused by different conditions of the information inside the boiler. But should we open a valve the model inside the boiler changes, opening the valve is a mathematical singularity as conditions have changed, the old model defining the flow of currents has changed, conditions have changed. Opening the valve of a boiler might be introducing a singularity, a breakdown of the old models, but it is predictable and even though at the moment of opening the valve the currents become chaotic, in general there is a decrease in pressure due to the opening of the valve. The difficulty in economics has to do with predicting when the valve will open, we know exactly when it will open in a boiler, a human being will do it, but economics needs a far deeper understanding of the singularity to predict when the singularity will occur.

Besides the deep concerns of predictability laid out above, the prediction of an economy on a month to month basis has had far more success than its failures, the prediction of the GDP, failing when there is a singularity, when the models breakdown because of "opening the valve", a significant change in the variables. Not as accurate as predicting stress levels on less complex information like a steel rod, but predictable enough, inflation is largely tamed for societies respecting economics. Complex information is less stable, human information packages usually break down before a human reaches 100 years old, humans wither away and die eventually. The sun is less complex and will eventually die in a few more billion years. Even a tree that lives to 2000 years old is but an information package from yesterday as compared to the sun, the tree is less predictable then the sun, where exactly is the next branch appearing? If we cannot answer this, is plant biology then not a science?

To be more clear for those with a different mindset one can say "being scientific means building an "adequate”, in a precise sense, model of reality, sort of adaptation” (Andrew Miloradovsky) [12]. But we must realize a model of reality can only be based on information, if it exists it is information. Information can never be false in a scientific sense, when false information is taken as real, one can in every manner call it mysticism, even if it is based on the soundest of mathematical principles, it is not the mathematical principles that reality is based on, it is based on information, to say the universe is mathematics is fancy and shocking, but wrong. Understanding reality becomes clearer the more information we extract, mathematics being an excellent tool for us to understand the interaction of information. When we light a fire how long does a one-liter pot of water take to heat given certain atmospheric conditions. Note both water and fire are information. Atmospheric conditions are information, the water container is information, the fuel for the fire is information, mathematics helps to explain the relationship, helps us understand reality, but is not reality in and of itself. Mathematics has successfully explained the relationship of price and goods. The price is information, the good is information.

\section{References}

[1] Halligan, L. (2013) Time to Stop This Pretence-Economics Is Not Science. The Telegraph, London.

[2] Singh, A. (2015) Economics Is an Art, Not a Science. Fair Observer. www.fairobserver.com

[3] Figueroa, L. (2014) Is Economics a Science? If Not, What Is It? Quora. www.quora.com

[4] Nasa, S. (2011) Is Economics a Science? If Not, What Is It? Quora. www.quora.com

[5] Farmer, J.D., Shubik, M. and Smith, E. (2009) Is Economics the Next Physical Science. Physics Today. www.physicstoday.org 
[6] Focardi, S.M. (2015) Is Economics an Empirical Science? If Not, Can It Become One? Frontiers in Applied Mathematics and Statistics. http://www. frontiersin.org

[7] Muon, R. (2015) Physics of Information - Quantum Entanglement, Black Holes and Holographic Universe Youtube. www.youtube.com

[8] Robbins, L. (1945) An Essay on the Significance of Economic Science. MacMillan and Co., London.

[9] Khumalo, B. (2012) Defining Economics in the Twenty First Century. Modern Economy, 3, 597-607. http://dx.doi.org/10.4236/me.2012.35079

[10] Khumalo, B. (2007) Point X and the Economics of Knowledge. Ideas. https://ideas.repec.org/p/pra/mprapa/3735.html

[11] Khumalo, B. (2012) The Concept of the Mathematical Infinity and Economics. Modern Economy, 3, 798-809. http://dx.doi.org/10.4236/me.2012.36102

[12] Khumalo, B. (2016) Quantum Physics Discussion. Google + https://plus.google.com/u/0/112435056666315189014/posts/TTo3zNa97QS 